\title{
Toxicity and Evidence for Metabolic Alterations in 2,3,7,8-Tetrachlorodibenzo-p-dioxin-Treated Guinea Pigs Fed by Total Parenteral Nutrition ${ }^{1,2}$
}

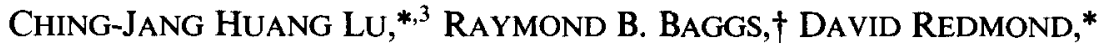 \\ ELLEN C. HENRY, ${ }^{*}$ ARNOLD SCHECTER, $\ddagger$ AND THOMAS A. GASIEWICZ ${ }^{* 4}$
}

\begin{abstract}
*Division of Toxicology, Department of Radiation Biology and Biophysics, and + Division of Laboratory Animal Medicine, The University of Rochester School of Medicine, Rochester, New York 14642; and $\ddagger$ Department of Preventive Medicine, Upstate Medical Center, State University of New York, Binghamton, New York 13901
\end{abstract}

Received November 5, 1985; accepted March 3, 1986

\begin{abstract}
Toxicity and Evidence for Metabolic Alterations in 2,3,7,8-Tetrachlorodibenzo-p-dioxin-Treated Guinea Pigs Fed by Total Parenteral Nutrition. Huang Lu, C.-J., BaGGs, R. B., Redmond, D., Henry, E. C., SChecter, A., AND Gasiewicz, T. A. (1986). Toxicol. Appl. Pharmacol. 84, 439453. The effect of total parenteral nutrition (TPN) on the toxicity of 2,3,7,8-tetrachlorodibenzop-dioxin (TCDD) in male, Hartley-strain guinea pigs was determined. At a single dose of $2 \mu \mathrm{g}$ $\mathrm{TCDD} / \mathrm{kg}$, TPN-fed guinea pigs maintained body weight at a level which was slightly, but consistently, below that of the TPN-fed control animals. However, despite the sustenance of body weight, TCDD-treated animals died or were sacrificed due to morbidity between Days 8 and 24 following treatment. Approximately $50 \%$ of this group demonstrated a profound loss of body weight within a few days prior to death or sacrifice. With the exception of the pattern of weight loss, the signs of toxicity in the TPN-fed, TCDD-treated animals were strikingly similar to those observed in TCDD-treated guinea pigs fed ad libitum. Although livers from TCDD-treated, TPNfed animals demonstrated increased content of lipid and cytochrome $P-450$, this tissue appeared to be morphologically and functionally comparable to that from TPN-fed controls. Of the blood chemistry examined, only the serum concentrations of 3,5,3'-triiodothyronine were significantly decreased in the treated animals fed by TPN. Results were also compared to TCDD-treated guinea pigs fed ad libitum and respective pair-fed controls. Many of the physiological and biochemical responses observed in animals fed ad libitum following TCDD treatment could be explained by a decrease in food consumption. This study demonstrated that although food consumption clearly accounts for the major effect of TCDD on body weight loss in guinea pigs fed ad libitum, additional physiological and/or biochemical alterations occurred which also contribute to body weight loss, other signs of toxicity, and subsequent lethality. (c) 1986 Academic Press, Inc.
\end{abstract}

\footnotetext{
1 Supported in part by Grant ES-02859 and Center Grant ES-01247 from the National Institute of Environmental Health Sciences, and Grant R809627010 from the Environmental Protection Agency. This paper is also based on work performed under Contract DE-ACO2-76EV3490 with the United States Department of Energy at the University of Rochester Department of Radiation Biology and Biophysics and has been assigned Report UR-3490-2505.

${ }^{2}$ Presented in part at the 24th Annual Meeting of the Society of Toxicology (Toxicologist 5, 250, 1985).

${ }^{3}$ Present address: Department of Agricultural Chemistry, Laboratory of Nutritional Chemistry, National Taiwan University, Taipai, Taiwan.

${ }^{4}$ To whom requests for reprints should be addressed.
}

The chlorinated dibenzo- $p$-dioxins are among the most toxic synthetic chemicals and are known to elicit a variety of biochemical and biological responses in a number of mammalian species (Poland and Knutson, 1982). Of these responses, a starvation-like or wasting syndrome is one which is most consistently observed (Gupta et al., 1973; McConnell et al., 1978; Greig et al., 1973). This syndrome occurs following a single dose of 2,3,7,8-tetrachlorodibenzo- $p$-dioxin (TCDD, the most toxic isomer), is dose dependent, and is characterized by chronic and progressive weight 
loss or decreased weight gain. When a lethal dose of TCDD is administered, the body weight loss prior to death may be as much as 30 to $40 \%$ of the original body weight. However, the dose of TCDD necessary to produce this response varies considerably with the mammalian species examined: from less than $1 \mu \mathrm{g} / \mathrm{kg}$ for the guinea pig (McConnell et al., 1978) to nearly $5000 \mu \mathrm{g} / \mathrm{kg}$ in the hamster (Olson et al., 1980). Although initial studies suggested that hypophagia was not great enough to account for all of the weight loss (Harris et al., 1973; Gasiewicz et al., 1980; Ball and Chhabra, 1981), more recent studies indicate that a decrease in food consumption accounts for nearly all, if not all, of the body weight lost by TCDD-treated rats (Seefeld and Peterson, 1983; Seefeld et al., 1984a).

Although loss in body weight may be a major contribution to TCDD-induced lethality, the relative involvement of other factors such as biochemical and/or metabolic alterations is unknown. Considering the magnitude of body weight loss as well as the chronic nature of the response, it is very difficult to dissect these relative contributions since many observed changes may be secondary to decreased food consumption and the wasting syndrome. In an attempt to resolve these difficulties, we previously have examined the effects of TCDD treatment in rats which were fed intravenously by a total parenteral diet (TPN) (Gasiewicz et al., 1980). These studies indicated that nutrients could be used effectively, but not necessarily efficiently, by TCDD-treated rats for the maintenance of body weight in a manner similar to that observed in TPN-fed control animals. However, although the general trend in body weight gain in TCDD-treated, TPNfed animals was similar to the TPN-fed controls, TCDD-induced alterations of specific pathways for nutrient utilization may have occurred under these experimental conditions. This appears to have been likely since (1) although the intravenous feeding protected against TCDD-induced body weight loss, lethality was still observed; (2) the relative stores of adipose tissue were greater in the TCDD- treated, TPN-fed group as compared to the TPN-fed controls; (3) hypoglycemia and increased concentrations of serum lipids were observed in the TCDD-treated animals despite the continuous infusion of TPN fluid containing approximately $70 \%$ of the caloric intake as dextrose; and (4) the TCDD-treated, TPNfed group exhibited a relatively significant degree of hepatocellular damage with concomitant lipid accumulation. Because of the severe nature of the hepatic damage, even as compared to TCDD-treated animals fed ad libitum, interpretation of the protective nature of the TPN feeding was limited to the general effect upon body weight.

The present study examined the effect of TCDD treatment in guinea pigs which were fed by TPN. Little or no hepatic damage has been observed in this species (fed ad libitum) following TCDD treatment (McConnell et al., 1978). Therefore, this model may be more appropriate for the examination of some of the primary effects of TCDD without those which may be secondary to body weight loss or due to extensive hepatic damage. The results from this study indicated that although a decrease in food consumption may be a significant factor contributing to the wasting syndrome and subsequent lethality in TCDD-treated animals, other unidentified metabolic alterations occurred which promoted and contributed to the toxicity observed.

\section{METHODS}

Animals. Hartley-strain guinea pigs were purchased from Charles River Breeding Laboratories (Wilmington, Mass.). These animals were housed under laboratory conditions with a 12-hr light cycle for at least 5 days prior to use. During this period they were fed commercial chow (Agway Prolab Guinea Pig Diet, Agway Inc., Syracuse, N.Y.) and water ad libitum. Animals were divided into eight groups: group 1, control animals fed and watered $a d$ libitum; group 2, TCDD treated fed ad libitum; group 3, pair-fed control; group 4, TCDD 
treated, TPN fed; group 5, TPN-fed control; group 6, saline infused, fed ad libitum; group 7, TCDD treated, saline infused, fed ad libitum; and group 8, saline-infused, pair-fed control. The saline-infused groups were used to determine the effect of the chronic, intravenous administration of large volumes of fluid as occurs in the TPN-fed animals. Body weights of the pair-fed control animals were matched as closely as possible to the appropriate TCDD-treated group. Initial mean ( \pm SD) body weights for these respective groups were: group 1, $302 \pm 17$; group 2, 313 \pm 32 ; group 3, $308 \pm 19$; group 4, $330 \pm 12$; group 5, $326 \pm 18$; group 6, $322 \pm 16$; group $7,311 \pm 17$; and group $8,308 \pm 14$. All animals were housed individually in suspended, stainless-steel cages, and pair feeding was performed using a method similar to that described by Seefeld et al. (1984a). The amount of food eaten per day was determined as the amount of food taken from the feed tray, carefully accounting for any spillage which occurred. Pair-fed control animals were also given the same amount of water lost from the bottles corresponding TCDD-treated group, not accounting for water spillage. Dosing solutions of TCDD (98\% pure) (Cambridge Isotope Laboratories, Woburn. Mass.) were prepared in olive oil as described previously (Gasiewicz et al., 1980). Guinea pigs in each group were treated with a single intraperitoneal dose of $2 \mu \mathrm{g} \mathrm{TCDD} / \mathrm{kg}$ body wt or an equal volume of olive oil.

Intravenous solutions. The TPN solutions were prepared aseptically in $250-\mathrm{ml}$ vacuum sealed glass containers and stored at $4^{\circ} \mathrm{C}$ prior to use. Table 1 shows the contents of the TPN solution. The amino acids were supplied in an injection preparation (Aminosyn, Abbott Laboratories, North Chicago, Ill.). Vitamins, with the exception of vitamin B-12, folic acid, and $p$-aminobenzoic acid, were supplied in Multi Vitamin Concentrate (Lypho-Med, Inc., Chicago, Ill.). Animals were supplemented with $2.5 \mathrm{ml}$ of Liposyn $10 \%$ (Abbott Laboratories) injected as a bolus into the intravenous line. Phytonadione (AquaMEPHYTON,
TABLE 1

Composition of the Total Parenteral Nutrition Fluid USED for Guinea Pigs

\begin{tabular}{|c|c|}
\hline Component & Amount/liter \\
\hline L-Isoleucine & $3.02 \mathrm{~g}$ \\
\hline L-Leucine & $3.95 \mathrm{~g}$ \\
\hline L-Lysine & $3.02 \mathrm{~g}$ \\
\hline Methionine & $1.68 \mathrm{~g}$ \\
\hline L-Phenylalanine & $1.85 \mathrm{~g}$ \\
\hline L-Threonine & $2.18 \mathrm{~g}$ \\
\hline L-Tryptophan & $0.67 \mathrm{~g}$ \\
\hline L-Valine & $3.36 \mathrm{~g}$ \\
\hline L-Alanine & $5.38 \mathrm{~g}$ \\
\hline L-Arginine & $4.12 \mathrm{~g}$ \\
\hline L-Histidine & $1.26 \mathrm{~g}$ \\
\hline L-Proline & $3.61 \mathrm{~g}$ \\
\hline L-Tyrosine & $0.18 \mathrm{~g}$ \\
\hline L-Serine & $1.76 \mathrm{~g}$ \\
\hline Glycine & $5.38 \mathrm{~g}$ \\
\hline Dextrose & $231 \mathrm{~g}$ \\
\hline Potassium & $53.4 \mathrm{meq}^{a}$ \\
\hline Acetate & $148 \mathrm{meq}$ \\
\hline Chloride & $48 \mathrm{meq}$ \\
\hline Sodium lactate & $50 \mathrm{meq}$ \\
\hline Ascorbate acid & $250 \mathrm{~g}$ \\
\hline Vitamin A & $5000 \mathrm{IU}$ \\
\hline Vitamin D & $500 \mathrm{IU}$ \\
\hline Thiamine $\mathrm{HCl}$ & $25 \mathrm{mg}$ \\
\hline Riboflavin & $5 \mathrm{mg}$ \\
\hline Pyridoxine $\mathrm{HCl}$ & $7.5 \mathrm{mg}$ \\
\hline Niacinamide & $50 \mathrm{mg}$ \\
\hline Dexpanthenol & $12.5 \mathrm{mg}$ \\
\hline Vitamin E & $2.5 \mathrm{IU}$ \\
\hline Vitamin B-12 & $20 \mu \mathrm{g}$ \\
\hline Folic acid & $4 \mathrm{mg}$ \\
\hline$p$-Aminobenzoic acid & $40 \mathrm{mg}$ \\
\hline Choline $\mathrm{HCl}$ & $0.3 \mathrm{~g}$ \\
\hline Calcium gluconate & $5 \mathrm{~g}$ \\
\hline Magnesium sulfate & $0.3 \mathrm{~g}$ \\
\hline Zinc sulfate & $1.2 \mathrm{mg}$ \\
\hline Cupric chloride & $0.36 \mathrm{mg}$ \\
\hline Manganous chloride & $0.72 \mathrm{mg}$ \\
\hline Sodium iodide & $0.12 \mathrm{mg}$ \\
\hline Sodium selenite & $0.4 \mathrm{mg}$ \\
\hline
\end{tabular}

ancludes $2.3 \mathrm{meq} / \mathrm{liter}$ for the antioxidant, potassium metabisulfite.

Merck Sharp and Dohme, West Point, Pa.) $(500 \mu \mathrm{g})$ was administered intravenously every fourth day. A more complete description of this nutrient solution and its preparation has 
been made (Huang Lu et al., unpublished work).

Catheterization technique and TPN feeding. The technique for catheterization of the guinea pig jugular vein was a modification of the method previously described for rats (Gasiewicz et al., 1980) incorporating the aseptic techniques described by Popp and Brennan (1981). These techniques as specifically modified for the guinea pig are more fully described elsewhere (Huang Lu et al., unpublished work). Immediately following surgery, the infusion of sterile, $0.9 \%(\mathrm{w} / \mathrm{v})$ saline was started and gradually increased over a 3-day period to a maximal rate of $70-75 \mathrm{ml} /$ day. The guinea pigs were allowed access to commercial chow ad libitum for the first 3 days, after which it was withdrawn and the infusion of the TPN diet started. In the case of the saline-infused animals, the intravenous administration of saline was continued. TCDD or olive oil was administered to the animals at Day 5 following the start of TPN infusion. Daily maintenance procedures for all animals included determination of body weight and infusion flow rate, observation for qualitative gross or behavioral abnormalities, and, where needed, complete inspection of the catheter assembly. In some cases animals were removed from infusion due to swelling in the neck area or loss of patency of the catheter. In the former case, infection and/or the leaking of fluid subcutaneously were often the causative factors. These events occurred in less than $25 \%$ of the postsurgical animals, and were readily apparent within 3 days following insertion of the cannula. These animals were not included in the data analysis.

Animal sacrifice and histopathology. Animals were killed under carbon dioxide anesthesia by exsanguination via heart puncture. The blood was allowed to coagulate at room temperature and the serum removed and frozen at $-20^{\circ} \mathrm{C}$ for later analyses. Approximately 5-10 min elapsed from the time the TPN or saline was discontinued until exsanguination. Tissues were excised, weighed, and sections from liver, kidney, pituitary, brain, adrenal, pancreas, stomach, intestine, heart, lungs, thymus, spleen, testes, muscle, urinary bladder, thyroid, and bone marrow were examined for histopathology. Tissues were fixed in phosphate-buffered $10 \%$ Formalin, embedded in paraffin, sectioned at $5 \mu \mathrm{m}$, and stained with hematoxylin and eosin. Periodic acidSchiff(PAS) and oil red-O stains were also used on hepatic sections. Hepatic sections were blindly scored on the basis of fat content (oil red-O staining), glycogen content (PAS staining), and necrosis. For electron microscopy, animals were perfused by heart puncture with $0.1 \mathrm{M}$ phosphate buffer, $\mathrm{pH} 7.2,4 \%(\mathrm{w} / \mathrm{v})$ paraformaldehyde, $3 \%(\mathrm{v} / \mathrm{v})$ glutaraldehyde. Liver fragments were fixed in phosphate buffer containing $3 \%$ glutaraldehyde and $4 \%$ paraformaldehyde, postfixed in osmium, washed in phosphate buffer, dehydrated through sequential graded ethanol mixtures, and then through several rinses of $100 \%$ ethanol. These were placed in propylene oxide, propylene oxide and epoxy resin, pure epoxy resin, and baked overnight. Sections were cut on an automated ultramicrotome using a diamond knife set for 600-1200 A sections. Sections were placed on uncoated grids, stained with uranyl acetate and lead citrate, and examined using a Philips 201 electron microscope at $60 \mathrm{kV}$.

Tissue analysis. A portion of the liver was used for the determination of protein, lipid, DNA, water, and total cytochrome $P-450$. Total water content was determined as the difference between wet and dry weights of sections approximately $0.5-1.0 \mathrm{~g}$ wet wt. Total lipids were extracted by the method of Folch et al., (1957) and determined gravimetrically after drying under a stream of nitrogen. The remaining tissue was homogenized in 3 volumes of buffer containing $50 \mathrm{mM}$ potassium phosphate, $\mathrm{pH} 7.6$, and $1 \mathrm{mM}$ EDTA. Protein was determined by the method of Markwell et al. (1978) using bovine serum albumin as a standard. DNA content was determined by the method described by Labrea and Paigen (1980) using calf thymus DNA as a standard. Cytochrome $P-450$ concentration in the microsomal pellet $(150,000 \mathrm{~g}, 1 \mathrm{hr})$ was deter- 
mined by the method of Omura and Sato (1964).

Analysis of serum for chloride, sodium, phosphate, creatinine, bilirubin, total protein, alkaline phosphatase, transaminases [glutamic oxaloacetic (GOT) and pyruvic (GPT)], albumin, globulin, lactate dehydrogenase, triglycerides, glucose, blood urea nitrogen, and calcium were measured using standard Technicon SMAC methods (Technicon Instruments Corporation, 1976). These were carried out by VetPath Corporation (Teterboro, N.J.). Total serum cholesterol was determined by the method of Allain et al. (1974) using the phenol and 4-aminoantypyrine chromogenic system described by Trinder (1969). Thyroxine $\left(\mathrm{T}_{4}\right)$ and 3,5,3'-triiodothyronine $\left(\mathrm{T}_{3}\right)$ were determined using Coat-A-Count $T_{3}$ and $T_{4}$ double antibody kits (Diagnostic Products Corporation, Los Angeles, Calif.).

Statistical analysis. Statistical analysis for differences among groups was performed using the Cochran $t$ test (Cochran and Cox, 1975). The analysis for differences among growth rates of the animal groups was performed by analysis of variance.

\section{RESULTS}

\section{Body Weights and Gross Appearances}

Figure 1 shows the time course of body weight changs of TCDD-treated and control guinea pigs fed ad libitum. Six of the ten animals administered TCDD demonstrated a consistent pattern of body weight loss within a few days following treatment. (Hereafter, these animals will be designated as "sensitive.") This progressesd into the characteristic wasting syndrome with animals losing from 30 to $40 \%$ of their original body weight prior to being sacrificed. Individual body weight and food consumption data for three representative animals from this group as well as their respective pair-fed controls are shown in Fig. 2 . In every case, body weight alterations for the pair-fed controls closely paralleled those

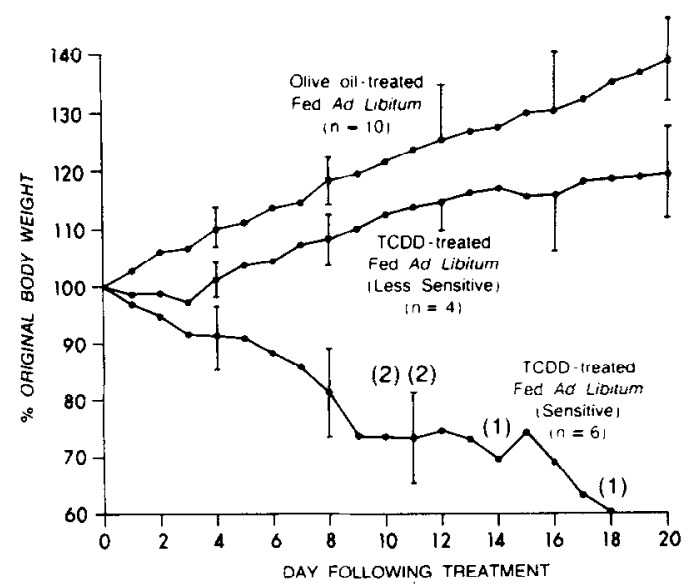

FIG. 1. Time-related changes in body weight in control and TCDD-treated guinea pigs fed ad libitum. Male guinea pigs were treated on Day 0 with $\operatorname{TCDD}(2 \mu \mathrm{g} / \mathrm{kg})$ or vehicle. Each point represents the $\bar{x}$ of $n$ animals. The SD is indicated by the vertical lines at Days $4,8,11,12,16$, and 20 . Numbers in parentheses indicate the number of animals sacrificed due to morbidity.

of the TCDD-treated guinea pigs until just a few days prior to sacrifice, during which the treated animals lost weight at a greater rate. Four of the ten TCDD-treated animals, however, failed to lose body weight, but continued to grow at a rate which was slightly lower than the control animals fed ad libitum (Fig. 1). (Hereafter, these animals will be designated as "less sensitive.") The respective pair-fed control animals for this group showed nearly identical body weight gains (data not shown.)

Guinea pigs which were saline-infused but allowed to eat ad libitum demonstrated weight gains (not shown) which were nearly identical to those observed for animals fed and watered ad libitum $(6.12 \pm 1.32$ and $6.33 \pm 1.18 \mathrm{~g} /$ day, respectively). These data indicated that there is minimal effect in these animals from catheter implantation, possible sepsis, or the infusion of large volumes of fluid (Huang $\mathrm{Lu}$ et al., unpublished work). Saline infusion also had no apparent effect upon the time course or signs of TCDD-induced toxicity in animals fed ad libitum. Saline-infused guinea pigs treated with TCDD exhibited a similar pattern of body weight loss (not shown) as observed 

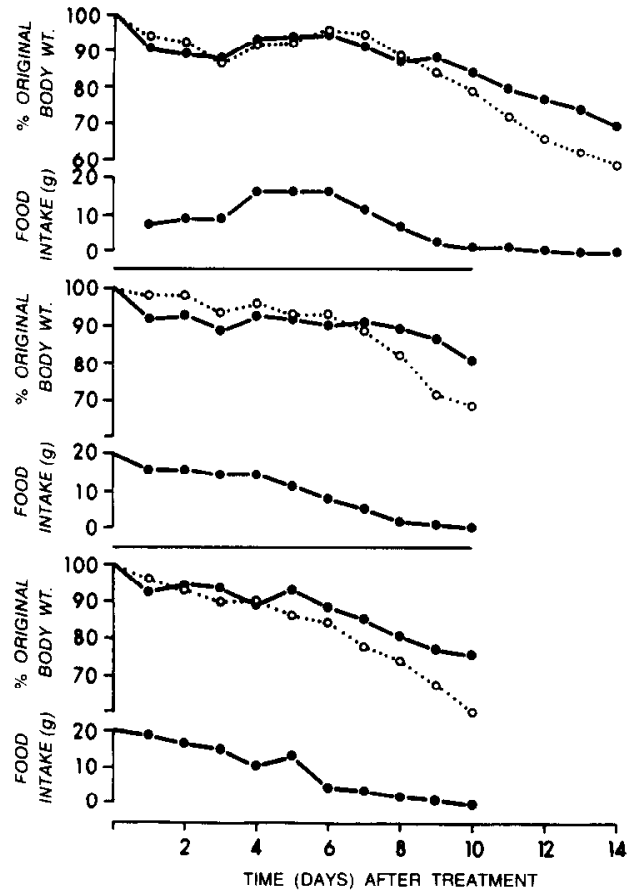

FIG. 2. Time-related changes in body weight and food consumption in representative TCDD-treated guinea pigs fed ad libitum $(O)$ and their respective pair-fed controls (๑). Treatment was the same as indicated in Fig. 1 legend. Feed intake was corrected for spillage.

in TCDD-treated animals fed and water ad libitum. Likewise, comparative body weight alterations in TCDD-treated, saline-infused animals, and their respective pair-fed controls were similar to that observed in the animals allowed oral intake of water (Fig. 2), i.e., within the last few days prior to sacrifice the respective TCDD-treated group lost slightly more body weight.

As noted previously, (Huang Lu et al., unpublished work), a decrease in body weight gain was observed in the TPN-fed group immediately upon changing from saline to TPN infusion (Figs. 3 and 4). However, this trend was reversed by Day 5 of TPN infusion, after which a consistent mean weight gain of 4.06 $\pm 1.46 \mathrm{~g}$ /day was observed for the olive oiltreated control animals (Fig. 3). Within approximately 10 days following the start of the TPN infusion some of the animals exhibited diarrhea, but this could be reduced considerably by allowing these animals to chew on ashless cellulose tablets. With this exception, the TPN-fed control animals appeared to be quite normal and active as compared to the groups fed ad libitum. In all cases, the TCDDtreated, TPN-fed animals never demonstrated the samc increase in body weight as the control animals (Figs. 3 and 4). Despite the maintenance of body weight, all guinea pigs in this group died $(5 / 19)$ or were sacrificed due to morbidity from days 8 to 24 following treatment. Approximately $50 \%$ of this group demonstrated a profound loss of body weight within a few days prior to death or sacrifice

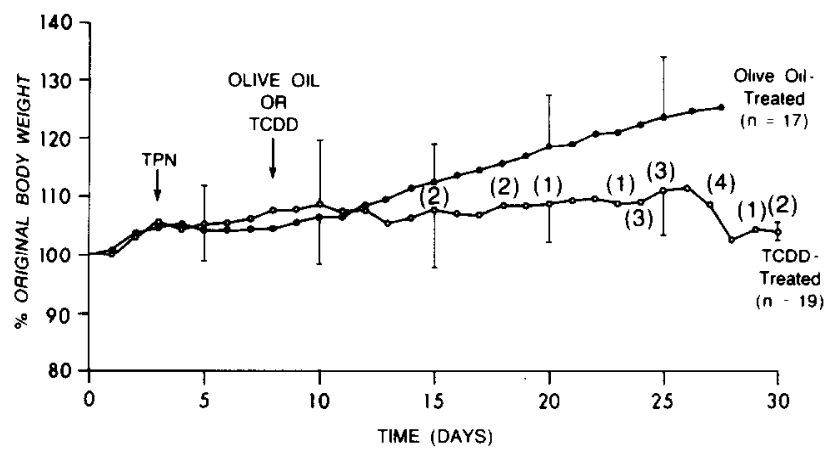

FIG. 3. Time-related changes in body weight in control and TCDD-treated guinea pigs fed by TPN. Male guinea pigs were treated with TCDD $(2 \mu \mathrm{g} / \mathrm{kg})$ on Day 6 (5 days following the start of the TPN infusion). Each point represents the $\bar{x}$ of $n$ animals. The SD is indicated by the vertical lines at Days $5,10,15,20,25$, and 30 . Numbers in parentheses indicate the number of animals dying or sacrificed due to morbidity. 


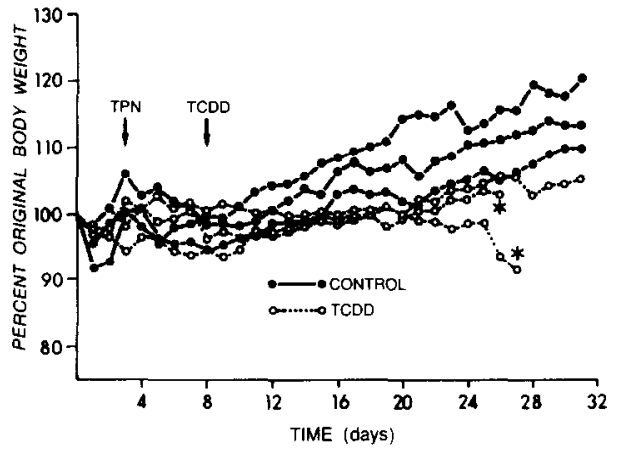

Fig. 4. Time-related changes in body weight in representative control and TCDD-treated guinea pigs fed by TPN. Treatment was the same as described for Fig. 3 . *Indicates animal death.

(Fig. 4). As in the control animals, the TCDDtreated group exhibited diarrhea, although it was more persistent and severe. These animals also showed excessive salivation, decreased activity, and generally poor appearance. With the exception of the lack of continuous body weight loss, this appearance was like that observed for TCDD-treated guinea pigs fed ad libitum.

It was of interest to determine if TCDDtreated animals would still demonstrate decreased food consumption and body weight loss upon discontinuation of the TPN feeding. Animals (3) were placed on the TPN diet and treated with TCDD according to the schedule as described above. At Day 8 following TCDD treatment the TPN feeding was discontinued and replaced by saline infusion and the animals were allowed to feed ad libitum. In every case, and despite the gain in weight observed during TPN feeding, all of these animals exhibited a loss in body weight following the discontinuation of TPN (data not shown). In contrast, vehicle-treated animals subjected to this same procedure demonstrated an increased food consumption and body weight gain following the start of saline infusion and oral food consumption. An attempt was also made to change to TPN infusion 8 days following TCDD treatment of animals which were fed ad libitum but saline infused. In these cases, and as expected, all animals showed a slight loss in body weight prior to TPN infusion. However, TPN infusion did not prevent the continued loss in body weight. All of these animals exhibited a greater rate of body weight loss and died within 4 days following the start of TPN infusion.

\section{Tissue Weights and Histopathology}

Although alterations in tissue weights were observed in TCDD-treated animals fed ad libitum as compared to both pair-fed and ad libitum fed controls (Table 2), all of these differences could be explained mainly by a decrease in food consumption. There was an increase in the relative weights of liver, kidney, and adrenal in the TCDD-treated sensitive group as compared to their respective pair-fed controls. However, these differences are likely due to the slight difference in body weight between these two groups (Fig. 1) since no differences were observed when total tissue weights were compared (Table 3 for liver weights, other data not shown). Other tissue weights on an absolute or relative basis were similar between these two groups. Values for relative liver and kidney weights were also increased in TCDD-treated, saline-infused sensitive animals as compared to their respective pair-fed control group (data not shown). Again, however, these values were not different when compared on an absolute basis. All tissue weights from the TCDD-treated, less-sensitive animals were not significantly different as compared to those from the respective pairfed control group (data not shown). Only the values for relative liver weight, but not absolute weight, of the TCDD-treated, TPN-fed animals were significantly increased as compared to the TPN-fed control group (Tables 4 and 5). However, it should be observed that TPN feeding to control animals significantly increased relative liver and adrenal weights and decreased testicular and epididymal adipose 
TABLE 2

Tissue Weights in TCDD-Treated and Control Guinea Pigs Fed aD Libitum ${ }^{a}$

\begin{tabular}{lcccc}
\hline \multicolumn{1}{c}{ Tissue } & $\begin{array}{c}\text { Control, fed } \\
\text { ad libitum (6) }\end{array}$ & $\begin{array}{c}\text { TCDD-treated } \\
\text { (less sensitive) (3) }\end{array}$ & $\begin{array}{c}\text { TCDD-treated } \\
\text { (sensitive) (4) }\end{array}$ & $\begin{array}{c}\text { Control, pair } \\
\text { fed (4) }\end{array}$ \\
\hline Liver & $3.60 \pm 0.20$ & $4.59 \pm 0.30^{b}$ & $4.71 \pm 0.29^{b, d}$ & $3.16 \pm 0.20^{b}$ \\
Kidney & $0.83 \pm 0.05$ & $0.84 \pm 0.05^{c}$ & $1.35 \pm 0.12^{b, d}$ & $1.04 \pm 0.10^{b}$ \\
Testes & $0.45 \pm 0.06$ & $0.44 \pm 0.06^{c}$ & $0.28 \pm 0.06^{b}$ & $0.23 \pm 0.07^{b}$ \\
Adrenal & $0.042 \pm 0.007$ & $0.052 \pm 0.004^{b . c}$ & $0.096 \pm 0.009^{b . d}$ & $0.064 \pm 0.004^{b}$ \\
Epididymal adipose & $0.44 \pm 0.07$ & $0.42 \pm 0.04^{c}$ & $0.13 \pm 0.06^{b}$ & $0.11 \pm 0.08^{b}$ \\
Perirenal adipose & $1.27 \pm 0.32$ & $1.01 \pm 0.39^{c}$ & $0.22 \pm 0.13^{b}$ & $0.18 \pm 0.14^{b}$ \\
\hline
\end{tabular}

${ }^{a}$ Values are expressed as $\mathrm{g} / 100 \mathrm{~g}$ body wt and are the $\bar{x} \pm \mathrm{SD}$ of $(n)$ animals. The pair-fed group indicated was pair fed to TCDD-treated animals which were sensitive. No significant differences were observed for the weights of spleen, heart, or lung.

${ }^{b-d}$ Significantly different $(p<0.05)$ as compared to: ${ }^{b}$ the group fed and watered ad libitum; ${ }^{c}$ the TCDD-treated sensitive group; ${ }^{d}$ the pair-fed control group.

TABLE 3

Liver Composition in TCDD-Treated and Control Guinea Pigs Fed aD Libituma

\begin{tabular}{|c|c|c|c|c|}
\hline & $\begin{array}{l}\text { Control, fed } \\
\text { ad libitum (6) }\end{array}$ & $\begin{array}{c}\text { TCDD-treated } \\
\text { (less sensitive) (3) }\end{array}$ & $\begin{array}{l}\text { TCDD-treated } \\
\text { (sensitive) }(4)\end{array}$ & $\begin{array}{l}\text { Control, pair } \\
\text { fed (4) }\end{array}$ \\
\hline \multicolumn{5}{|l|}{ Liver wt: } \\
\hline $\mathrm{g} / 100 \mathrm{~g}$ body $\mathrm{w}$ & $3.6 \pm 0.2$ & $4.6 \pm 0.3^{b}$ & $4.7 \pm 0.3^{b, d}$ & $3.2 \pm 0.2^{b}$ \\
\hline $\mathrm{g}$ & $17.3 \pm 1.5$ & $18.0 \pm 1.6^{c}$ & $9.0 \pm 0.8^{b}$ & $7.8 \pm 1.8^{b}$ \\
\hline \multicolumn{5}{|l|}{ Protein: } \\
\hline $\mathrm{mg} / \mathrm{g}$ & $228.2 \pm 26.9$ & $228.0 \pm 3.4$ & $181.0 \pm 38.5$ & $164.4 \pm 15.7^{b}$ \\
\hline $\mathrm{mg} / \mathrm{mg}$ DNA & $39.7 \pm 2.8$ & $40.8 \pm 0.6^{r}$ & $30.8 \pm 5.9^{b}$ & $27.5 \pm 6.0^{b}$ \\
\hline \multicolumn{5}{|l|}{ Lipid: } \\
\hline $\mathrm{mg} / \mathrm{g}$ & $40.9+3.1$ & $56.8+4.4^{b}$ & $55.6 \pm 6.6^{b, d}$ & $44.6+1.4$ \\
\hline $\mathrm{mg} / \mathrm{mg}$ DNA & $7.1 \pm 0.5$ & $10.7 \pm 0.3^{b}$ & $9.5 \pm 1.0^{b, d}$ & $6.7 \pm 0.8$ \\
\hline \multicolumn{5}{|l|}{ DNA: } \\
\hline $\mathrm{mg} / \mathrm{g}$ & $5.76 \pm 0.36$ & $5.59 \pm 0.11$ & $5.89 \pm 0.57$ & $6.73 \pm 0.58^{b}$ \\
\hline $\mathrm{mg} /$ tissue & $99.6 \pm 9.9$ & $100.6 \pm 8.8^{c}$ & $53.2 \pm 8.8^{b}$ & $52.4 \pm 12.8^{b}$ \\
\hline \multicolumn{5}{|l|}{ Water: } \\
\hline $\mathrm{mg} / \mathrm{g}$ & $713 \pm 15$ & $678 \pm 9^{b}$ & $710 \pm 21$ & $705 \pm 23$ \\
\hline $\mathrm{mg} / \mathrm{mg}$ DNA & $125 \pm 7$ & $123 \pm 4$ & $122 \pm 14$ & $106 \pm 13$ \\
\hline \multicolumn{5}{|c|}{ Microsomal protein: } \\
\hline $\mathrm{mg} / \mathrm{g}$ & $19.8 \pm 4.2$ & $29.8 \pm 2.5^{b}$ & $33.5 \pm 1.8^{b, d}$ & $28.1 \pm 1.9$ \\
\hline $\mathrm{mg} / \mathrm{mg}$ DNA & $3.4 \pm 0.5$ & $5.3 \pm 0.5^{b}$ & $5.8 \pm 0.4^{b, c}$ & $4.2 \pm 0.5$ \\
\hline \multicolumn{5}{|c|}{$\begin{array}{l}\text { Cytochrome } P-450 \text { : } \\
\text { nmol/mg microsomal }\end{array}$} \\
\hline protein & $1.56 \pm 0.30$ & $2.52 \pm 0.40^{b}$ & $2.16 \pm 0.17^{b, d}$ & $0.91 \pm 0.32^{b}$ \\
\hline $\mathrm{nmol} / \mathrm{mg}$ DNA & $5.44 \pm 0.76$ & $13.4 \pm 1.6^{b}$ & $12.6 \pm 0.4^{b, d}$ & $3.74 \pm 1.06^{b}$ \\
\hline
\end{tabular}

${ }^{a}$ Values are expressed as $\bar{x} \pm \mathrm{SD}$ of $(n)$ animals.

${ }^{b-d}$ Significantly different $(p<0.05)$ as compared to: ${ }^{b}$ the group fed and watered ad libitum; ${ }^{c}$ the TCDD-treated (sensitive) group; ${ }^{d}$ the pair-fed control group. 
TABLE 4

TISSUE WEIGHTS IN TCDD-TREATED AND CONTROL Guinea PIGS FED BY TPN ${ }^{a}$

\begin{tabular}{|c|c|c|}
\hline Tissue & Control (13) & TCDD-treated (8) \\
\hline Liver & $4.95 \pm 1.09^{\circ}$ & $7.13 \pm 1.43(14)^{b}$ \\
\hline Kidney & $0.87 \pm 0.11$ & $0.90 \pm 0.12$ \\
\hline Testes & $0.21 \pm 0.08^{c}$ & $0.20 \pm 0.04$ \\
\hline Adrenal & $0.061 \pm 0.009^{c}$ & $0.060 \pm 0.02$ \\
\hline $\begin{array}{c}\text { Epididyma } \\
\text { adipose }\end{array}$ & $0.30 \pm 0.05^{c}$ & $0.30 \pm 0.03$ \\
\hline $\begin{array}{l}\text { Perirenal } \\
\text { adipose }\end{array}$ & $0.92 \pm 0.29$ & $1.03 \pm 0.26$ \\
\hline
\end{tabular}

${ }^{a}$ Values are expressed as $\mathrm{g} / 100$ body wt and are the $\bar{x}$ $\pm \mathrm{SD}$ of $(n)$ animals. No significant differences were observed in the weights of spleen, heart, or lung.

${ }^{b}$ Significantly different $(p<0.05)$ as compared to the control group.

${ }^{c}$ Significantly different $(p<0.05)$ as compared to the group fed and watered ad libitum (Table 2).

tissue weights as compared to animals fed and watered ad libitum (Tables 2 and 4).

As determined by light microscopy, only liver and the tissue surrounding the catheter in saline- and TPN-infused animals demonstrated a consistent differential morphologic pattern. When respective control groups were compared, no other tissues demonstrated significant morphological lesions which could be ascribed to TCDD treatment. The area surrounding the external continuation of the cannula exhibited a localized inflammatory process with fibrosis and edema. This was observed in both saline-infused and TPN-fed animals, with or without TCDD treatment. Livers from TCDD-treated sensitive animals fed ad libitum, with or without saline infusion, contained numerous sharply delimited vacuoles associated with parenchymal cells mainly of the centrilobular region. The presence of these presumptive lipid vacuoles was confirmed by electron microscopy and oil red-O staining. The preponderance of these vacuoles was not observed in livers from control or TCDD-treated less-sensitive animals. While livers from the TCDD-treated less-sensitive groups contained modest to abundant quan- tities of PAS-positive materials in the centrilobular region, the material was deficient in livers from the TCDD-treated sensitive animals. However, livers from the respective pairfed control groups showed similar qualitative differences in PAS-positive staining. Livers from all TPN animals contained increased quantities of PAS-positive material as well as lipid vacuoles. These have been more thoroughly described previously (Huang Lu et al., unpublished work). However, there were no apparent qualitative differences between the amount or distribution of these materials in livers from TCDD-treated or control TPN-fed animals. Proliferation of smooth endoplasmic reticulum was observed by electron micros-

TABLE 5

LIVER COMPOSITION IN TCDD-TREATED AND Control Guinea Pigs fed by TPN ${ }^{a}$

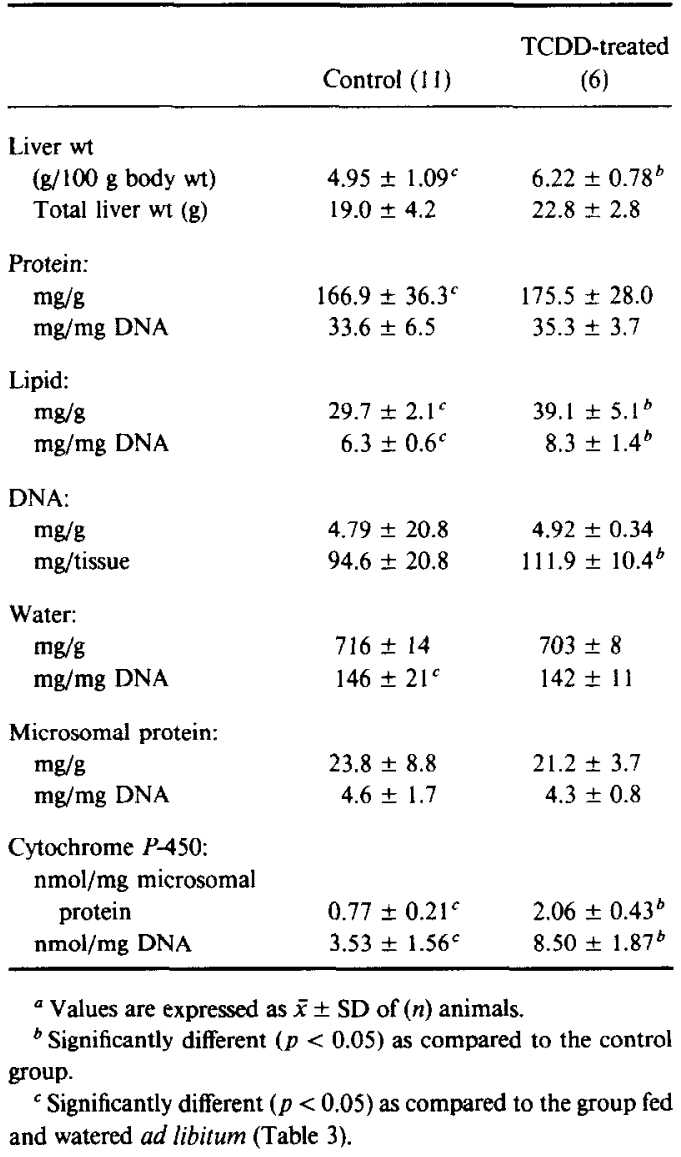


copy in all TCDD-treated animals as compared to their respective pair-fed controls. Hepatic necrosis was not observed in any TCDDtrcated guinea pig in this study.

\section{Blood Chemistry}

No statistical differences were observed between TCDD-treated and their respective control groups for the following determinations in serum: calcium, sodium, chloride, phosphate, blood urea nitrogen, creatinine, total bilirubin, total protein, albumin, globulin, alkaline phosphatase, lactate dehydrogenase (LDH), SGPT, SGOT, and glucose. However, differences were observed in the serum lipid values (Table 6). TCDD treatment to animals fed ad libitum consistently resulted in increased serum cholesterol and triglyceride concentrations. This effect was also observed in less-sensitive TCDD-treated animals which were fed ad libitum (data not shown). Serum cholesterol and triglyceride levels in the TCDD-treated, TPN-fed animals were not increased as compared to the TPN-fed control

TABLE 6

SERUM LIPIDS IN TCDD-TREATED AND Control Guinea Pigs ${ }^{a}$

\begin{tabular}{lcc}
\hline \multicolumn{1}{c}{ Group } & $\begin{array}{c}\text { Cholesterol } \\
(\mathrm{mg} / \mathrm{dl})\end{array}$ & $\begin{array}{c}\text { Triglyceride } \\
(\mathrm{mg} / \mathrm{dl})\end{array}$ \\
\hline $\begin{array}{c}\text { Control, fed } a d \\
\text { libitum (6) }\end{array}$ & $44.8 \pm 22.0$ & $133.0 \pm 26.9$ \\
$\begin{array}{l}\text { TCDD treated, fed } \\
\quad \text { ad libitum (6) }\end{array}$ & $146.8 \pm 66.1^{b, c}$ & $247 \pm 98.7^{b, c}$ \\
$\begin{array}{l}\text { Pair-fed control (6) } \\
\text { Saline infused, fed } a d\end{array}$ & $64.2 \pm 13.3$ & $108.7 \pm 29.6$ \\
$\quad$ libitum (7) & $49.3 \pm 6.6$ & $124.5 \pm 34.1$ \\
$\begin{array}{l}\text { TCDD treated, saline } \\
\text { infused (3) }\end{array}$ & $233.0 \pm 58.3^{b-d}$ & $177.0 \pm 55.1$ \\
$\begin{array}{l}\text { Saline-infused, pair- } \\
\text { fed control (3) }\end{array}$ & $68.7 \pm 4.2^{d}$ & $61.9 \pm 38.1^{b}$ \\
$\begin{array}{l}\text { TCDD treated, TPN } \\
\text { fed (9) }\end{array}$ & $48.4 \pm 15.6$ & $95.1 \pm 20.1^{b}$ \\
TPN-fed control (12) & $50.3 \pm 37.6$ & $72.7 \pm 17.4^{b}$ \\
\hline
\end{tabular}

\footnotetext{
a Values are expressed as $\bar{x} \pm$ SD of $(n)$ animals.

${ }^{b-d}$ Significantly different $(p<0.05)$ as compared to: ${ }^{b}$ animals fed and watered ad libitum; ' appropriate pair-fed control group; ${ }^{d}$ saline-infused animals fed ad libitum.
}

guinea pigs. However, it should be noted that triglyceride concentrations in the TPN-fed control group were significantly decreased as compared to those in the group fed and watered ad libitum.

Limited food intake, as occurred in the TCDD-treated sensitive group and their respective pair-fed controls, appeared to cause a depression in the serum concentrations of both $T_{4}$ and $T_{3}$ concentrations (Table 7 ). However, when compared to their respective pair-fed controls, TCDD-treated animals fed ad libitum showed no alterations in serum $\mathrm{T}_{3}$ or $\mathrm{T}_{4}$ concentrations under these conditions. Serum $\mathrm{T}_{4}$ concentrations in both control and TCDD-treated guinea pigs fed by TPN were below the level of detection for the assay used. Although serum concentrations of $T_{3}$ for the control TPN-fed group were similar to the orally fed animals, these values for the TCDDtreated, TPN-fed group were consistently below the level of detection.

\section{Liver Composition}

A decreased food intake by the TCDDtreated sensitive group fed ad libitum and their respective pair-fed controls resulted in a decrease in the total weight of the liver as compared to controls fed ad libitum or the TCDDtreated less sensitive animals (Table 3 ). There was also a concomitant decrease in the total liver content of DNA as well as the relative concentrations of protein. Treatment with TCDD, however, produced consistent increases in the concentrations of hepatic lipid, microsomal protein, and cytochrome $P-450$ as comparcd to the controls which were fed ad libitum or pair-fed. These differences were significant whether calculated on the basis of per gram wet weight of tissue or per milligram DNA. When the liver compositions of the TCDD-treated sensitive and less sensitive animals were compared, only the values for total protein and DNA were significantly different. However, as noted above, this could be explained primarily by decreased food con- 
TABLE 7

SERUM THYROID HORMONE CONCENTRATIONS IN TCDD-TREATED AND CONTROL Guinea Pigs Fed Orally OR by TPN ${ }^{a}$

\begin{tabular}{lll}
\multicolumn{1}{c}{ Group } & \multicolumn{1}{c}{$\mathrm{T}_{\mathbf{3}}(\mathrm{ng} / \mathrm{dl})$} & \multicolumn{1}{c}{$\mathrm{T}_{\mathbf{4}}(\mu \mathrm{g} / \mathrm{dl})$} \\
\hline Control, fed ad libitum & $29,37,46,31$ & $2.6,3.0,2.9,2.4$ \\
TCDD treated, fed ad libitum (less sensitive) & 46,33 & $3.7,2.3$ \\
Pair-fed control (less sensitive) & 33,25 & $3.3,2.4$ \\
TCDD treated, fed ad libitum (sensitive) & $<20,25,35,27$ & $1.5,1.5,1.2,1.1$ \\
Pair-fed control (sensitive) & $23,26,32,<20$ & $1.5,1.3,<1,1.3$ \\
TCDD treated, TPN fed & $<20(5)$ & $<1(6)$ \\
TPN-fed control & $26,44,32,26$ & $<1(4)$ \\
\hline
\end{tabular}

${ }^{a}$ Individual values are shown except in cases where all values $(n)$ were below value indicated.

sumption since the pair-fed control group also showed these same differences as compared to the TCDD-treated less-sensitive group. Nearly identical comparative results as described above were observed for the groups which were saline infused and fed ad libitum (data not shown).

Hepatic concentrations of lipid and cytochrome $P-450$ were the only values which were significantly increased by TCDD treatment in TPN-fed animals (Table 5). However, it should be noted that TPN feeding caused a relative decrcase in the liver content of total protein, lipid, and cytochrome $P-450$ as compared to guinea pigs fed ad libitum (Tables 3 and 5). This may be explained partially by the significant increase in hepatic water content as well as glycogen in the livers from TPN-fed animals.

\section{DISCUSSION}

Results from the present study are in good agreement with those previously reported (Seefeld et al., 1984a,b; Kelling et al., 1985) which indicate that both TCDD-treated rats and guinea pigs fed ad libitum lose body weight to a similar extent as the respective pair-fed controls. Although discussed previously (Seefeld et al., 1984a), this data reemphasizes the importance of utilizing a properly pair-fed control group for whole-animal studies in- volving TCDD and related halogenated hydrocarbons. Feed spillage must be accounted for when determining daily food consumption of treated animals. Without this correction, it would be difficult to make an accurate assessment of the role of food consumption in the wasting syndrome elicited by TCDD. Furthermore, alterations which were a consequence of decreased food consumption and/ or body weight loss would not be distinguished from any primary effects of TCDD exposure. In the present study, a number of the responses of guinea pigs fed ad libitum to TCDD trcatment appeared to be mainly, if not exclusively, secondary to decreased food intake and/or body weight loss. These include changes in the weights of certain tissues (Table 2), decreased hepatic content of DNA and protein (Table 3 ), and decreased serum concentrations of $\mathrm{T}_{3}$ and $\mathrm{T}_{4}$ (Table 7 ).

Individual, as opposed to group, pair feeding is also necessary due to animal variations in their response to TCDD. Male guinea pigs treated with $2 \mu \mathrm{g} \mathrm{TCDD} / \mathrm{kg}$ could be divided into two groups, sensitive and less sensitive, based primarily on their food consumption and subsequent body weight loss (Fig. 1). The reason for this clear separation of relative responsiveness to TCDD is not known, but also has been observed in TCDD-treated rats (Rozman, 1984a,b; Sweatlock and Gasiewicz, unpublished work; Peterson, personal communication). The relative frequency of this 
differentiation in rats is likely dose related since at a higher dose a greater percentage of the animals could be categorized as sensitive (Sweatlock and Gasicwicz, unpublished work). Although the dose of TCDD used in this study is the same as the reported LD50 value for this age, sex, species, and strain of guinea pig (McConnell et al., 1978), there may be considerable variation in sensitivity depending on the commercial supplier as well (Walden and Schiller, 1985). There were some noteworthy similarities and differences between the TCDD-treated sensitive and less-sensitive groups fed ad libitum. Both groups demonstrated comparable increases in serum lipids, as well as increased hepatic content of lipid, cytochrome $P-450$, and microsomal protein over their respective pair-fed controls. Thus, although these are noted biochemical responses to TCDD, they could not be causally associated with toxicity, decreased food consumption, or body weight loss observed in the sensitive group. Notably however, while the relative valucs for hepatic lipid content, as determined by complete solvent extraction, were similar for the TCDD-treated sensitive and less-sensitive groups (Table 3 ), a significant centrilobular accumulation of lipid vacuoles was observed by light microscopy only in the TCDD-treated sensitive group. Although increased serum and hepatic lipids in both groups indicated an alteration in the regulation of lipid metabolism, additional biochemical and/or distributional differences of lipid in the livers from the sensitive group may be due, in part, to the extensive mobilization of extrahepatic fat stores observed in the group. The only clear difference observed between these two groups was the loss in body wcight.

An important finding of the present study was that TCDD-treated, TPN-fed guinea pigs were able to utilize intravenously fed nutrients to maintain body weight. This finding extended that previously observed in TPN-fed rats (Gasiewicz et al., 1980), without the extenuating feature of severe hepatic damage. With the exception of increased hepatic content of cytochrome $P-450$ and lipid, the livers from TCDD-treated, TPN-fed guinea pigs appeared to be morphologically and functionally comparable to the TPN-fed controls. However, and as observed previously for rats (Gasiewicz et al., 1980), protection against TCDDelicited toxicity or lethality was not observed in guinea pigs despite the maintenance of body weight by feeding a TPN diet. In fact, the TPNfed, TCDD-treated guinea pigs exhibited nearly identical signs of toxicity, with the exception of body weight loss, as TCDD-treated animals fed ad libitum. This result indicated that although decreased food consumption clearly accounts for the major effect of TCDD on body weight loss in guinea pigs fed ad libitum, additional alterations are occurring which also contribute significantly to body weight loss, other signs of toxicity, and subsequent lethality.

Recently, a model has been proposed for the effect of TCDD on body weight regulation (Seefeld et al., 1984b). This proposal suggested that TCDD causes a reduced regulation level or "set point" for body weight. The finding that TCDD-treated guinea pigs fed ad libitum or by TPN consistently lost slightly more body weight than respective controls may be consistent with this hypothesis in that at a given level of body weight the relative efficiency of feed utlization or fluid regulation may be comparatively less in a TCDD-treated animal (Seefeld and Peterson, 1984; Kelling et al., 1985). The additional finding that TPN-fed guinea pigs, despite the maintenance of body weight, still succumb to the toxicity of TCDD is also consistent with this hypothesis if one considers, as previously suggested (Seefeld $e t$ al., 1984b), that a dietary condition, i.e., TPN feeding, which is isocaloric for untreated animals, becomes hypercaloric to TCDD-treated animals. Thus, certain metabolic pathways are unable to adjust to accommodate the TPN diet, and so it is detected as hypercaloric and essentially becomes toxic to the animal. This caloric overload in TPN-fed, TCDD-treated rats (Gasiewicz et al., 1980) has been viewed (Seefeld $e t$ al., 1984b) as an explanation for the excessive accumulation of adipose tissue 
and potentiated hepatotoxicity in this species. However, neither of these responses have been observed in the present investigation using TPN-fed guinea pigs. This is not unexpected since little or no hepatic damage has been observed in TCDD-treated guinea pigs fed ad libitum (McConnell et al., 1978), and there are likely numerous species-specific differences in the control of energy metabolism. In this context, hypoglycemia has also been shown to occur in TCDD-treated rats (Gasiewicz et al., 1980), but not in treated guinea pigs (Gasiewicz and Neal, 1979). However, in addition to the observation that toxicity and lethality still occur in TCDD-treated guinea pigs fed by TPN, a further suggestion that these animals had lost the metabolic ability to adapt to the diet is derived from the experiment in which TCDD-treated, saline-infused animals were placed on the TPN diet. All of these animals, and unlike untreated controls, were apparently unable to adjust to this diet since rapid body weight loss continued and death was observed within a few days following the start of TPN infusion. This response is strikingly similar to the result observed by Brewster and Matsumuara (1984). In this case, all TCDD-treated guinea pigs (fed ad libitum) died within a few hours following the single administration of a large amount of glucose.

$\Lambda$ lthough these observations suggest an overall inability of TCDD-treated animals to metabolically adjust to certain nutritional changes, it is our view that some of the responses observed are indeed adaptive responses rather than primary causes of toxicity. Unfortunately, however, some of these adaptive responses which are prolonged become themselves toxic to the animal and eventually exacerbate the primary metabolic effects caused by TCDD. In the case of animals fed ad libitum, an adjustment of feeding behavior occurs in an attempt to compensate for a TCDD-induced metabolic and/or biochemical alteration causing a reduced "set point" of body wcight regulation. At a lethal dose, a further adjustment beyond that of totally eliminating food consumption cannot be made. Under these circumstances, both the metabolic alteration and starvation contribute to lethality. The finding that hypophagia does not appear to be the major contributor to lethality (Kelling et al., 1985) in C57BL/6J mice is an indication of the species-specific nature of this adaptive response. Under conditions of TPN feeding, the animal cannot adjust feeding behavior, so the primary metabolic alteration persists to eventually result in overt toxicity and death. In this case and under the specific metabolic conditions of TPN feeding, however, other species-specific adaptive responses may occur. For the TPN-fed rat, excessive accumulation of adipose tissue occurs in an attempt to adjust to the "hypercaloric" nature of the diet (Gasiewicz et al., 1980). Again, that this particular metabolic response is not primary to the wasting syndrome caused by TCDD is suggested by the findings of the present study that excessive accumulation of adipose tissue was not apparent in TPN-fed guinea pigs. However, in TPN-fed guinea pigs, a decreased serum concentration of thyroid hormones, in particular $T_{3}$, may have been an adaptive response to TCDD treatment. This response also has been shown to occur in TCDD-treated rats fed ad libitum (Rozman et al., 1984) and is viewed as an adaptive response rather than a primary mechanism of toxicity since (1) thyroidectomy gives some, but not full, protection against TCDD-elicited lethality (Rozman et al., 1984); (2) the administration of $\mathrm{T}_{4}$ to thyroidectomized, TCDD-treated rats results in increased toxicity (Rozman et al., 1984); (3) alteration in serum concentrations of $T_{3}$ and $T_{4}$ were not observed in TCDD-treated guinea pigs fed ad libitum (Table 7); and (4) hyper- rather than hypothyroidism has been observed in hamsters following TCDD treatment (Henry and Gasiewicz, unpublished work). Thus, although the primary metabolic effect caused by TCDD which leads to the wasting syndrome may be the same in most species, subsequent adaptive responses which are dependent upon the specics as well as metabolic and nutritional states may result in varied ultimate causes of death in ex- 
perimental animals. We are not suggesting that all of the toxic effects observed following TCDD exposure are due exclusively to one metabolic alteration. This appears unlikely given the multifaceted and tissue-specific nature of these effects (Poland and Knutson, 1982). However, it is clear that many of the responses, adaptive or primary, are involved in the regulation of energy metabolism at the whole-animal level.

Although the present results may be consistent with a previously proposed model implicating a TCDD-elicited alteration in body weight regulation, it is unclear at this time what the identities of the primary metabolic alterations are or at what biochemical or physiological level these may occur. As has been observed (Seefeld et al., 1984b), some, but not all, of the signs of TCDD toxicity bear a striking resemblance to those caused by certain hypothalamic lesions. However, signals from the hypothalamus are under control of a variety of other metabolic and hormonal factors. Thus, if the hypothalamus is involved in mediating the wasting syndrome elicited by TCDD, it is uncertain whether the effect of TCDD is direct or secondary to some other metabolic alteration.

\section{ACKNOWLEDGMENTS}

We thank George Rucci and Susan Reynolds for technical assistance, Henry Eichelberger for the preparation of tissues for electron microscopy, Linda Johnstone for the preparation of tissues for light microscopy, Joyce Morgan for the manufacture of the animal harnesses, and Dr. Christopher Cox for assistance with statistical analysis.

\section{REFERENCES}

Allain, C. A., POON, L. S., Chan, C. S. G., Richmond, W., AND FU, P. C. (1974). Enzymatic determination of total serum cholesterol. Clin. Chem. 20, 470-475.

BALL, L. M., AND CHHABRA, R. S. (1981). Intestinal absorption of nutrients in rats treated with 2,3,7,8-tetrachlorodibenzo-p-dioxin TCDD. J. Toxicol. Environ. Health 8, 629-638.

Brewster, D. W., and Matsumura, F. (1984). TCDD (2,3,7,8-tetrachlorodibenzo-p-dioxin) reduces lipoprotein lipase activity in the adipose tissue of the guinea pig. Biochem. Biophys. Res. Commun. 122, 810-817.

Cochran, W. G., AND Cox, G. M. (1975). Experimental Designs, pp. 158-159. Wiley, New York.

FolCH, J., LEES, M., AND STANLEY, G. H. S. (1957). A simple method for the isolation and purification of total lipids from animal tissues. J. Biol. Chem. 226, 497509.

Gasiewicz, T. A., Holscher, M. A., AND Neal, R. A. (1980). The effect of total parenteral nutrition of the toxicity of 2,3,7,8-tetrachlorodibenzo-p-dioxin in the rat. Toxicol. Appl. Pharmacol. 54, 469-488.

GASIEWICZ, T. A., AND NEAL, R. A. (1979). 2,3,7,8-Tetrachlorodibenzo- $p$-dioxin tissue distribution, excretion, and effects on clinical chemical parameters in guinea pigs. Toxicol. Appl. Pharmacol. 51, 329-339.

GREIG, J. B., JoNES, G., BUTLER, W. H., AND BARNES, J. M. (1973). Toxic effects of 2,3,7,8-tetrachlorodibenzop-dioxin. Food Cosmet. Toxicol. 11, 585-595.

GuPTA, B. H., Vos, J. G., MoOre, J. A., ZINKL, J. G., AND Bullock, B. C. (1973). Pathologic effects of 2,3,7,8-tetrachlorodibenzo- $p$-dioxin in laboratory animals. Environ. Health Perspect. 5, 125-150.

HARRIS, M. W., MOORE, J. A., Vos, J. G., AND GuPTA, B. N. (1973). General biological effects of TCDD in laboratory animals. Environ. Health Perspect. 5, 101109.

Kelling, C. K., Christian, B. J., InhorN, S. L., AND Peterson, R. E. (1985). Hypophagia-induced weight loss in mice, rats, and guinea pigs treated with $2,3,7,8$ tetrachlorodibenzo-p-dioxin. Fundam. Appl. Toxicol. 5, $700-712$.

LABREA, C., AND PAIGEN, K. (1980). A simple, rapid, and sensitive DNA assay procedure. Anal. Biochem. 102, 344-352.

Markwell, M. K., HaAs, S. M., Bieber, L. L., AND TOLBERT, N. E. (1978). A modification of the Lowry procedure to simplify protein determination in membrane and lipoprotein samples. Anal. Biochem. 87, 206210.

McConnell, E. E., Moore, J. A., Haseman, J. K., AND HARRIS, M. W. (1978). The comparative toxicity of chlorinated dibenzo-p-dioxins in mice and guinea pigs. Toxicol. Appl. Pharmacol. 44, 335-356.

Olson, J. R., Holscher, M. A., AND NEAL, R. A. (1980). Toxicity of 2,3,7,8-tetrachlorodibenzo-p-dioxin in the golden Syrian hamster. Toxicol. Appl. Pharmacol. 55, 67-78.

OMURA, T., AND SATO, R. (1964). The carbon monoxide binding pigment of liver microsomes. J. Biol. Chem. 239, 2370-2378.

Poland, A., And KNutson, J. C. (1982). 2,3,7,8-'Tetrachlorodibenzo- $p$-dioxin and related halogenated aromatic hydrocarbons: Examination of the mechanism of toxicity. Annu. Rev. Pharmacol. Toxicol. 22, 517554. 
POPP, M. B. AND BRENNAN, M. F. (1981). Long-term vascular access in the rat: Importance of sepsis. Amer. $J$. Physiol. 241, H606-H612.

ROZMAN, K. (1984a). Separation of wasting syndrome and lethality caused by $2,3,7,8$-tetrachlorodibenzo-p-dioxin. Toxicol. Lett. 22, 279-285.

Rozman, K. (1984b). Hexadecane increases the toxicity of 2,3,7,8-tetrachlorodibenzo-p-dioxin (TCDD): Is brown adipose tissue the primary target in TCDD-induced wasting syndrome? Biochem. Biophys. Res. Commun. 125, 996-1004.

ROZMAN, K., ROZMAN, T., AND GREIM, H. (1984). Effect of thyroidectomy and thyroxine on 2,3,7,8-tetrachlorodibenzo-p-dioxin (TCDD)-induced toxicity. Toxicol. Appl. Pharmacol. 72, 372-376.

SEEFElD, M. D., CoRbeTt, S. W., KeESEY, R. E. AND Peterson, R. E. (1984a). Characterization of the wasting syndrome in rats treated with 2,3,7,8-tetrachlorodibenzo-p-dioxin. Toxicol. Appl. Pharmacol. 73, 311322.

Seefeld, M. D., Keesey, R. E., and Peterson, R. E. (1984b). Body weight regulation in rat treated with 2,3,7,8-tetrachlorodibenzo-p-dioxin. Toxicol. Appl. Pharmacol. 76, 526-556.

SeEfeld, M. D., AND Peterson, R. E. (1983). 2,3,7,8tetrachlorodibenzo-p-dioxin-induced weight loss: A proposed mechanism. In Human and Environmental Risks of Chlorinated Dioxins and Related Compounds (R. E. Tucker, A. L. Young, and A. Gray, eds.), pp. 405-413. Plenum, New York.

SEEFELD, M. D., AND Peterson, R. E. (1984). Digestible energy and efficiency of feed utilization in rats treated with 2,3,7,8-tetrachlorodibenzo-p-dioxin. Toxicol. Appl. Pharmacol. 74, 214-222.

Technicon Instruments Corporation (1976). Laboratory Method Files. Technicon Instruments Corporation, Tarrytown, N.Y.

TRINDER, P. (1969). Determination of blood glucose using 4-aminophenazone as an oxygen acceptor. $\mathrm{J}$. Clin. $\mathrm{Pa}$ thol. 22, 246.

WALDEN, R., AND SCHILler, C. M. (1985). Comparative toxicity of 2,3,7,8-tetrachlorodibenzo-p-dioxin (TCDD) in four (sub)strains of adult male rats. Toxicol. Appl. Pharmacol. 77, 490-495. 